\title{
Os Julgamentos por Amostragem ante o Contraditório
}

\author{
Sample Decisions Towards Contradictory
}

Fabio Victor de Aguiar Menezes ${ }^{1}$

${ }^{1}$ Escola Superior de Advocacia - ESA, Brasil

\section{Resumo}

A busca pela pacificação social com segurança jurídica levou a Jurisdição a transcender da esfera privada ao interesse de toda a comunidade. Paralelamente, o princípio do Contraditório presente no art. $5^{\circ}$, LV, da Constituição Federal evoluiu de uma vertente apenas formal de contraposição processual para um status substancial garantindo à parte o poder de influenciar efetivamente na solução da lide. No entanto, há uma falta de parâmetros para se garantir o efetivo contraditório, quando da aplicação do sistema

de julgamento por amostragem. A presente pesquisa objetiva analisar o fenômeno da coletivização das demandas individuais (espiritualização) presente na aplicação da técnica de julgamento por amostragem e trazer balizas para compatibilizar os julgamentos através de casos pilotos com o Contraditório Substancial, em busca da tutela jurisdicional, justa, adequada, efetiva e uniforme.

Palavras-chave: Coletivização das demandas individuais; Efetivo contraditório; Julgamentos por amostragem

\begin{abstract}
The search for social pacification with legal certainty led the Jurisdiction to transcend the private sphere to the interest of the entire community. At the same time, the Contradictory principle present in art. 5, LV, of the Federal Constitution evolved from a merely formal aspect of procedural opposition to a substantial status guaranteeing the party the power to influence effectively in the solution of the dispute. However, there is a lack of parameters to guarantee the effective contradiction, when applying the sampling judgment system. The present research aims to analyze the phenomenon of collectivization of individual demands (spiritualization) present in the application of the sampling judgment technique and to bring beacons to make judgments compatible with pilot cases with the Substantial Contradictory, in search of fair, adequate jurisdictional tutelage, effective and uniform.
\end{abstract}

Keywords: Collectivization of individual demands; Contradictory staff; Sampling trials

\section{Introdução}

A Constituição Federal de 1988 é um "standard" da democratização da jurisdição. O Espaço Jurídico Brasileiro é calcado na ampla proteção de direitos e na garantia praticamente irrestrita ao acesso à Justiça.

Porém, o princípio do acesso à Justiça impõe ao Judiciário que preste uma tutela jurisdicional adequada, uniforme e estável. Não é aceitável que para o mesmo objeto litigioso haja variáveis repostas jurisdicionais em sentidos, por vezes, díspares.

A desuniformidade das decisões judiciais brasileiras sobre a mesma questão de direito sempre foi e continua sendo criticada por doutrinadores, por aplicadores do direito e pela sociedade em geral. 
A problemática da insegurança jurídica brasileira ganha contornos mais severos com o incremento das ações de massa, que inundam o Judiciário de processos, sem que a Justiça consiga responder de forma célere, uniforme e estável.

Para tratar a tais questões em prol do interesse coletivo de maior segurança jurídica, o legislador brasileiro consolidou no CPC/2015 o chamado "microssistema de formação de precedentes", onde se inserem o Incidente de Assunção de Competência (artigo 947 do CPC), o Incidente de Resolução de Demandas Repetitivas (artigo 976 do CPC) e os Recursos Extraordinário e Especial Repetitivos (art. 1036 do CPC).

Assim, sob a nova legislação processual, existe a expressa obrigação de os juízes e os tribunais observarem os precedentes emanados de julgamento por amostragem dos Tribunais Superiores e dos Tribunais de $2^{\circ}$ grau (artigo 927 do CPC), como forma de uniformizar a jurisprudência e mantê-la estável, íntegra e coerente (artigo 926 do CPC).

Observa-se, neste contexto, que durante anos está havendo uma "Coletivização" das demandas individuais no Direito Processual Brasileiro através de institutos legais que permitem, um julgamento abstrato derivado de provocação concreta, retirando o objeto da lide da esfera privada para elevá-la à questão de interesse coletivo.

A problemática que se apresenta, é como compatibilizar, dentro de um efetivo contraditório, essa passagem de um processo subjetivo arquitetado para a solução de um caso de interesse individual ou privado, espiritualizando-o para uma relação processual que afetará toda coletividade abrangida pelo precedente a ser fixado com a aplicação da técnica do julgamento por amostragem.

\section{Um Novo Pensar Sobre a Teoria Tridimensional do Direito.}

A realidade a qual vivenciamos com todas a nuances de sistemas físicos, químicos, biológicos e sociais, está inserida em algo muito maior, para alguns equiparados ao divino, para outros fruto do acaso e para outros pura energia. O sistema jurídico, não é diferente, ele também está sujeito às leis que comandam o universo.

No final do século XVII, Isaac Newton desenvolveu a chamada lei da gravidade universal, proporcionando com ela a primeira descrição matemática da força que comanda todas as matérias existentes no universo e, pela sua precisão, até hoje é utilizada para calcular as trajetórias de objetos no espaço (GREENE, 2012, p. 25).

A precisão da teoria da gravidade de Newton é tão magnífica que levou Einsten a reformular sua teoria da relatividade para incluir a força gravitacional. O postulado de Einsten de que as leis da natureza devem parecer as mesmas para todos os observadores se deslocando livremente foi a base da teoria da relatividade, assim, chamada porque sugeria que apenas o movimento relativo era importante (HAWKING, 2016, p. 19).

Embora, a teoria da relatividade se adequasse bem às leis que governavam a eletricidade e o magnetismo, não era compatível com a lei da gravitação de Newton, pois esta dizia que se mudássemos a distribuição da matéria em uma região do espaço, a mudança no campo gravitacional seria instantânea por todo o universo. Tal constatação, permite que este efeito ocorresse numa velocidade superior à da luz e que houvesse um tempo absoluto ou universal, não aceito pela teoria da relatividade (HAWKING, 2016, p. 22).

Einsten, então, buscou saber como a gravidade funciona? e como seu poder interfere em corpos a milhões de $\mathrm{km}$ de distancia? A resposta baseada em uma matemática sofisticada e com saltos conceituais muito além do seu tempo, levou-o a uma resposta simples e genial: existe algo no espaço vazio: o espaço. O espaço seria o meio condutor da força gravitacional. (GREENE, 2012, p. 26)

Para Einsten, o espaço completamente vazio é muito semelhante a uma mesa plana e permite que os objetos se desloquem livremente em linha reta. Mas a presença de corpos dotados de massa afeta 
a formação do espaço. Assim, a curvatura do espaço causada pela massa do sol e dos planetas do sistema solar fariam moverem-se em óbitas (GREENE, 2012, p. 26).

A ideia de Einsten é que a massa e a energia deformariam não só o espaço mas também o espaçotempo. A gravidade, foi reconhecida por Einsten como a distorção do ambiente que é causada pela massa ou energia de um objeto que afeta os demais.

No Sistema Jurídico, Miguel Reale bem reproduziu o fenômeno do Direito com sua Teoria Tridimensional, onde descreve a realidade jurídica em uma unidade fático-axiológico-normativa.

Para Reale (2001, p.75), o Direito não é um sistema vazio, mas sim composto por: um fato subjacente (fato econômico, geográfico, demográfico, de ordem técnica etc.); um valor, que confere determinada significação a esse fato, inclinando ou determinando a ação dos homens no sentido de atingir ou preservar certa finalidade ou objetivo; e, finalmente, uma regra ou norma, que representa a relação ou medida que integra um daqueles elementos ao outro, o fato ao valor.

O grande jusfilósofo brasileiro afirma, acertadamente, que tais elementos ou fatores (fato, valor e norma) não existem separados um dos outros, mas coexistem numa unidade concreta e que que a vida do Direito resulta da interação dinâmica e dialética dos três elementos que a integram.

No entanto, com o perdão da ousadia e de forma humilde, propõe-se inserir o universo jurídico dentro da mesma lógica que se insere a relação do espaço com a gravidade. Sugere-se um novo pensar da teoria da trimensionalidade, incluindo como fator determinante na formação do Sistema Jurídico a massa de sujeitos que buscam a tutela do Direito.

O tempo demonstrou, por exemplo, que o aumento da massa de litigantes judiciais - assim como os corpos celestes no espaço - provocou diversas "deformações" no universo jurídico, alterando por vezes tanto o aspecto valorativo, quanto o aspecto fático e também o aspecto normativo.

Uma dessas evidências, aparece com o incremento massivo das Ações de Indenização por danos morais e o surgimento da ideia (aspecto valorativo) de que estaria ocorrendo uma banalização do referido instituto. Daí surgiu a jurisprudência batizada como a "indústria do dano moral", para abarcar os casos em que, de forma recorrente, o pedido daqueles que se sentiam lesados não correspondia ao que estava narrado e provado no processo. De igual forma nasceu a jurisprudência do mero aborrecimento.

No aspecto fático, em razão do melhor interesse da massa de pessoas atingidas pelo desastre de Mariana, o STJ no conflito de competência 164.362-MG houve por bem afastar sua jurisprudência predominante e aplicar a tese da competência adequada em detrimento do disposto legal para definir que o foro competente para julgamento desta Ação Popular seja o do local do fato em detrimento do domicílio do autor.

Nas palavras do Ministro Relator Ministro Francisco Falcão: "É verdade que, ao instituir a Ação Popular, o legislador constituinte buscou privilegiar o exercício da fiscalização e da própria democracia pelo cidadão. Disso não decorre, contudo, que as Ações Populares devem ser sempre distribuídas no foro mais conveniente a ele; neste caso, o de seu domicílio."

Da mesma forma, no âmbito normativo, com o aumento da litigiosidade em massa no Brasil, o Sistema Jurídico Brasileiro foi modificado, uma vez que a proliferação de uma grande massa de processos acabou por acentuar a morosidade do judiciário e a insegurança jurídica.

Para conter tal mal, o universo Jurídico modificou-se com o surgimento de normas disciplinando os processos coletivos, os incidentes de resolução de demandas repetitivas, de assunção de competências, os recursos especiais repetitivos, o recursos extraordinários repetitivos e a repercussão geral.

Por tanto, propõe-se que o universo jurídico deve sofrer também “modificações” em relação a massa de sujeitos a serem protegidos pelo Direito. Em silogismo, se é fato que todos os corpos modificam o universo, também é fato que a massa de sujeitos de direitos modifica o Universo Jurídico nas suas três estruturas (fato, valor e norma). 


\section{A Técnica De Julgamento Por Amostragem No Direito Brasileiro}

Já nos idos dos anos 70, Ada Pellegrini Grinover, aludindo aos ensinamentos de Goldschmidt, Calamandrei, Couture e Liebman, apontava inquestionável a sinergia existente entre a disciplina do processo e o regime constitucional vigente (GRINOVER, 1975, p. 3-4).

A Constituição de 1988, indubitavelmente, democratizou o Judiciário, ao consagrar no amplo rol de direitos fundamentais o acesso à justiça (art. 5º, XXXV) (BRASIL, 1988, n.p.). Historicamente a jurisdição foi concebida no pressuposto da ocorrência de litígio, necessariamente individual e evoluiu para assumir dimensões mais amplas para manter a paz social, passando a compreender, também, os fenômenos coletivos, em que os interesses transcendem a esfera do indivíduo e, de maneira difusa, alcançam toda a comunidade ou grandes porções dela.

Porém, o princípio do acesso à Justiça impõe ao Judiciário que preste uma tutela jurisdicional adequada, uniforme e estável. Marinoni demonstra um incômodo diante das variações de decisões, muitas vezes de um mesmo colegiado, acerca de uma mesma questão de direito:

Há algum tempo me incomodava a variações de decisões, muitas vezes de um mesmo colegiado, acerca de uma mesma questão de direito. Como sempre me preocupei com o senso comum a respeito do funcionalismo da justiça (MARINONI, 2016, p.13).

Ainda hoje se multiplicam decisões conflitantes e muito se deve a visão individualista clássica na qual o Direito Processual foi alicerçado. Nesse sentido, Marinoni aprofunda o problema nos seguintes termos:

O personalismo tem nítida relação com um sistema que privilegia as decisões individuais em detrimento das decisões da Corte que representa a vontade institucional, enquanto o patrimonialismo somente pode sobreviver num sistema irracional, em que os caso sejam tratados de forma particularizada, sem qualquer respeito à igualdade e a segurança jurídica (MARINONI, 2016, p.92).

Paralelo à questão da insegurança jurídica, Antônio Silveira Neto retrata a cultura da litigiosidade no Brasil, com uma alta concentração de ações repetitivas e de massa, o que proporciona a morosidade do judiciário:

No Brasil a cultura da litigiosidade, com uma alta concentração de ações repetitivas e ampla liberdade das partes de interposição dos mais diversos recursos contra qualquer decisão judicial, tem proporcionado um ambiente favorável à morosidade do Judiciário. A título de exemplo, entre os anos 2000 e 2001 existiam mais de 900.000 ações ajuizadas contra a Caixa Econômica Federal, tratando do mesmo tema: correção do saldo do FGTS nas contas dos trabalhadores em função dos índices inflacionários expurgados pelos Planos Bresser (julho de 1987), Verão (janeiro de 1989), Collor I (meses de abril e maio de 1990) e Collor II (fevereiro de 1991). E, conforme informou a própria Caixa Econômica na época, já haviam sido cumpridas mais de 400.000 decisões judiciais sobre esse assunto (SILVEIRA NETO, 2016, p. 220)

Em contrapartida, André Roque (2017, p. 26) aponta que em relação às demandas transindividuais, o ordenamento jurídico brasileiro foi fundado, basicamente, no quadripé formado pela Lei de Ação Popular (Lei n⿳o 4.717/1965), pela Lei da Ação Civil Pública (Lei no $7.347 / 1985$ ), pela Constituição da República de 1988 e pelo Código de Defesa do Consumidor (Lei no 8.078/1990). Entretanto, apesar dos avanços, a história demonstrou que tais normas não foram suficientes para responder a massificação de demandas, a insegurança jurídica e sanar a morosidade judicial.

Juliana Provedel (2018, p.87) aduz que para tratar tais questões em prol do interesse coletivo de maior segurança jurídica, o legislador brasileiro a partir da Constituição Federal começou a introduzir no ordenamento jurídico pátrio o exercício da jurisdição com base nos "precedentes judiciais, o que foi consolidado no CPC de 2015 através da técnica de julgamento por amostragem”. 
Neste contexto, a busca pela pacificação social com segurança jurídica, levou a Jurisdição a transcender da esfera privada e passou a ser de interesse de toda a comunidade. Ou seja, foi atingida a quantidade crítica de massa de demandantes que litigam sobre determinado direito ao ponto de modificar um dos três aspectos do Universo Jurídico (fato, valor e norma).

Neste contexto, o direito processual brasileiro transfigurou de instrumento de composição individual de conflitos para ampliar a solução do objeto litigioso para toda a coletividade, calcado na teoria dos precedentes, como mecanismo para responder os litígios de forma igualitária, coerente, segura e com previsibilidade das decisões judiciais

Portanto, durante anos está havendo uma Coletivização das demandas individuais no Direito Processual Brasileiro, fenômeno que também pode-se denominar de "Espiritualização do Processo". Tal expressão foi importada da Doutrina Criminal (ROXIN, 2006. p.410). que trata justamente da evolução do conceito de bem jurídico penalmente relevante da órbita apenas do indivíduo para toda a coletividade.

Tal "espiritualização" vem sendo observada quando os Tribunais Superiores aplicam a técnica de julgamento por amostragem prevista no art. 1.036 do CPC, "ex vi" a questão de ordem decidida no Recurso Especial nº 1.721.705- SP, de relatoria da Ministra Nancy Andrighi:

A partir daí, infere-se que o julgamento dos recursos submetidos ao STJ ultrapassa o interesse individual das partes nele envolvidas, alancando toda a coletividade para a qual suas decisões irradiam efeitos. Esse entendimento foi incorporado pelo CPC/15, ao dispor que "a desistência do recurso não impede a analise de questão cuja repercussão geral já tenha sido reconhecida e daquela objeto de julgamento de recursos extraordinários ou especiais repetitivos" (art. 998, parágrafo único) (STJ, 2018, n.p.).

No mesmo sentido, o STJ já possui precedentes com vistas à consolidação de teses de direito que transcendem o interesse individual da demanda (REsp 1555363/SP, Segunda Turma, DJe 07/10/2016; DESIS no AgRg na MC 22.582/RJ, Primeira Turma, DJe 22/05/2014; REsp 1308830/RS, Terceira Turma, DJe 19/06/2012; REsp 689.439/PR, Segunda Turma, DJe 22/03/2010; QO no REsp 1063343/ RS, Corte Especial, DJe 04/06/2009).

No Direito Processual Comparado, por sua vez, também já se encontra sedimentada a aplicação de técnicas que permitem que a tese de direito firmada por um precedente originário de uma demanda de interesse individual transcenda-se e alcance toda a coletividade:

Na Alemanha (o procedimento-modelo - Musterverfahren) se desenvolveu sem o abandono das tradicionais ações coletivas propostas por associações (Verbandsklagen). Da mesma forma, na Inglaterra, as decisões de litígios de grupo (group litigation order) que representam uma técnica de julgamentos de casos-piloto, foram previtas sem que fossem abolidas as ações representativas (representative action). Nos Estados Unidos, admite-se a utilização de procedimentos de casos-piloto sem prejuízo das class action (ROQUE, 2017. p. 39).

A expressão "precedentes judiciais" está intimamente ligada aos países adeptos à common law, cuja fonte principal do direito são as decisões proferidas pelos tribunais com base na teoria do stare decisis "os costumes foram se transformando, mediante um lento processo evolutivo, em direito jurisprudencial (TUCCI, 2004, p.10).

Por outro lado, de acordo com a sistemática adotada pelo CPC/2015 a aplicação dos precedentes é obrigatória por força da lei. Ou seja, o Código de Processo Civil vigente prevê de forma expressa e específica quais são os julgamentos que serão considerados precedentes (art. 927 do CPC) e não pela sedimentação dos costumes como norma jurídica.

De qualquer sorte, houve forte influência daquelas normas do direito estrangeiro, na construção do sistema de julgamento por amostragem alicerçado no Brasil desde o advento das Leis n⿳丷ㅜ11.418/2006 e 11.672/2008 ao acrescentarem os artigos 543-B e 543-C no CPC/1973 (BRASIL, 1973, n.p.), inaugurando o julgamento por amostragem dos recursos Extraordinário e Especial Repetitivos no âmbito dos Tribunais Superiores. 
Atualmente, o Código de Processo Civil de 2015 consolidou o sistema de julgamento por amostragem nos institutos de Incidentes de Assunção de Competência - IAC (artigo 947 do CPC), de Incidentes de Resolução de Demandas repetitivas - IRDR (artigos 976 a 987 do CPC) e em recursos especiais e extraordinários repetitivos (artigos 1.036 a 1.041 do CPC).

Em regra, o funcionamento das técnicas de julgamento por amostragem no direito processual brasileiro forma-se a partir de um conjunto de causas repetitivas, dentre as quais selecionam-se um caso representativo da controvérsia (causa-piloto ou modelo). Assevera Passo Cabral (2017, p. 37-38):

O primeiro é aquele das chamadas causas piloto ou processos teste, uma ou algumas causas que são selecionadas para julgamento, e cuja solução permite que se resolvam rapidamente todas as demais pela multiplicação da decisão. Este formato revela unidade cognitiva (o mesmo órgão que aprecia a questão comum julga o processo originário). (...) O segundo formato é aquele processo-modelo: neste, no incidente são apreciadas somente questões comuns a todos os casos similares, deixando a decisão de cada caso concreto para o juízo do processo originário. Ou seja, o que se observa neste segundo formato é cisão cognitiva e decisória.

Assim, a questão de direito é levada então para a instância superior para definição da tese jurídica que terá efeito vinculante. Estabelecida a tese jurídica, ela deverá ser aplicada a todos os processos que tratem de mesma questão jurídica, como forma de promover isonomia, segurança jurídica e celeridade processual.

Em relação ao incidente de assunção de competência há de se ressalvar que para ele não se exige a multiplicidade de demandas isonômica. Mas, pela relevância da questão e pela repercussão que sua resolução terá além dos limites subjetivos do processo, justifica-se a definição do precedente vinculante.

Neste contexto, a aplicação da técnica do julgamento por amostragem fortifica a coletivização do Direito Processual, com a fixação de uma tese jurídica geral, em simetria ao que ocorre em processos coletivos em que se discutem direitos individuais homogêneos.

Porém, Dierle Nunes (2018) atesta a existência de críticas ao modo superficial e mecânico como a técnica de formação de precedentes através do julgamento por amostragem que vem sendo utilizada pelos tribunais pátrios sem atender as balizas do Contraditório Substancial.

\section{O Princípio Constitucional do Contraditório}

Na atual concepção do Estado Democrático de Direito, o Direito Processual Civil Constitucional eleva o princípio do contraditório ao patamar de direitos e garantias fundamentais do cidadão, nos exatos termos do artigo 5o, LV, da Constituição Federal (BRASIL, 1988).

E mais ainda, o princípio do contraditório além de se constituir fundamentalmente em manifestação do próprio estado de direito, tem íntima ligação com a igualdade das partes e o próprio direito de ação e de defesa dos litigantes (NERY JUNIOR, 2004, p. 170).

A viabilização do contraditório, fortificada pelo art. 10 do novo CPC concretiza o Estado de Direito, dentro daquilo que se compreende como processo justo:

Dentro do Estado Constitucional, um Código de Processo Civil só pode ser compreendido como um esforço do legislador infraconstitucional para densificar o direito de ação como direito a um processo justo e, muito especialmente, como um direito à tutela jurisdicional adequada, efetiva e tempestiva dos direitos (MARINONI, 2010 , p. 16).

Com base nesta concepção do processo democrático e justo idealizado constitucionalmente, a definição de contraditório evoluiu de um aspecto formal de mera audiência bilateral das partes, para ser pleno e efetivo. Assim, para se ter um contraditório material é indispensável assegurar ao litigante não apenas o direito de ser ouvidos em juízo; mas a de lhe ser reconhecido e garantido também o direito 
de participar e influenciar, ativa e concretamente, da formação do provimento jurisdicional. Leonardo Greco leciona:

Em síntese, o contraditório do nosso tempo nada mais é do que a projeção no processo do primado da dignidade humana. Esse primado da dignidade humana impõe que o poder de influir nas decisões judiciais seja assegurado de fato, na prática, em concreto, e não apenas formalmente, a todos os interessados. Ora, não existe forma mais eficaz para isso, do que através da instauração de um diálogo humano entre o juiz e os outros sujeitos principais do processo, autor, réu e eventuais terceiros intervenientes. O diálogo e o intercâmbio de ideias entre duas ou mais pessoas humanas a respeito de qualquer questão ou problema. No diálogo todos os interlocutores falam, ouvem, dizendo o que pensam e reagindo às opiniões dos outros, de tal modo que ao seu término cada um deles influiu nas ideias do outro e por elas foi também influenciado. A transformação do processo em instância de diálogo certamente exige novo juiz, capaz não apenas de ouvir, mas também de escutar e de falar. Nesse aspecto, ação e defesa têm o mesmo conteúdo, como instrumentos de participação. Por outro lado, o contraditório participativo exalta a importância da oralidade, da publicidade e da fundamentação das decisões, como complementos necessários de um processo justo (GRECO, 2005, p. 241).

O contraditório deixa o tradicional binômio reducionista "informação-reação", passando a ser visto como instrumento de participação efetiva das partes no embate argumentativo com o estado-juiz de modo que possam influir decisivamente na produção do provimento judicial.

O elemento substancial do contraditório é o "poder de influência”. Portanto, para que se efetive o contraditório não basta que a parte tome ciência do processo e participe apenas sendo ouvida, é também necessário que a parte tenha condições de poder influenciar na decisão.

Porém, no caso da aplicação da técnica de julgamento por amostragem, existe uma séria dificuldade de se materializar esse poder de influência na passagem de um processo subjetivo arquitetado para a solução de um caso de interesse individual ou privado, espiritualizando-o para uma relação processual que afetará toda coletividade abrangida pelo precedente a ser fixado no processo piloto.

Assim, o que se vê no sistema de julgamento por caso piloto ou modelo é uma incompatibilidade com a garantia do contraditório, uma vez que a coisa julgada formada no julgamento do caso paradigma estenderia sua eficácia erga omnes, atingindo, portanto, quem não influenciou efetivamente na formação do precedente.

\section{Os Julgamentos por Amostragem ante ao Contraditório}

O respeito ao contraditório substancial é essencial na formação e na aplicação dos precedentes. Assim, tem-se a necessidade de se uniformizar e estabilizar a jurisprudência com a celeridade processual, sem que isso importe em prejuízo ao princípio constitucional do contraditório.

Para tanto, é necessário ter em mente que o contraditório efetivo, como todo princípio constitucional, não se trata de um valor absoluto e intangível, podendo então ser diferido ou, até mesmo, mitigado, desde que não represente efetivo prejuízo à parte.

Desta forma, é preciso traçar balizas a serem observadas em prol do efetivo contraditório, mesmo quando diferido, durante a aplicação da técnica de julgamento por amostragem quais sejam: (a) 5 a quantidade, a qualidade e a diversidade da argumentação do caso piloto (completude da discursão); (b) o contraditório efetivo na causa piloto; (c) a ampliada cognição no processo; (d) a participação dos terceiros afetados pelo provimento na formação da decisão judicial e (e) a representatividade adequada dos interessados.

\subsection{A qualidade, a quantidade e a diversidade da argumentação do caso piloto}

Dispondo de forma específica sobre cada um dos parâmetros para viabilizar o respeito ao princípio do contraditório efetivo quando da aplicação da técnica de julgamento por amostragem para 
formação de precedentes vinculantes, destaca-se inicialmente acerca da qualidade, da quantidade e da diversidade da argumentação do caso piloto.

Em síntese, refere-se à completude da discussão. É preciso que durante a formação do precedente sejam apreciados, inicialmente, todos os pontos de vista que possam infirmar a definição da questão jurídica através da técnica de julgamento por amostragem.

Definir uma tese em decisão paradigmática sem tomar em consideração um grupo mais completo dos fundamentos da pretensão e da defesa traz em si um duplo risco. Por um lado, a solução do incidente pode revelar-se equivocada porque justamente um daqueles argumentos não compreendidos no processo-teste poderia conduzir o Tribunal a uma conclusão diversa. E a decisão do incidente pode também ser menos eficiente, seja porque não vislumbrou uma possibilidade decisória, seja porque ao omitir-se sobre certos argumentos, deixa espaço para novos dissensos, podendo surgir, posteriormente, questionamentos no sentido de evitar a aplicação do incidente a processos pendentes (CABRAL, 2017, p. 49.).

Outro vetor a ser observado, no que se refere à completude da discussão, nos julgamentos por amostragem para se garantir o efetivo contraditório, é a seleção da causa-piloto pela qualidade dos argumentos.

Assim, se a linha argumentativa dos litigantes do processo de origem fundamentar o embate dialético entre as teses autorais e defensivas, a qualidade das alegações é fundamental para a escolha da causa piloto garantindo que os melhores argumentos com clareza, lógica e concisão formem um contraditório substancial.

Cabe frisar, que a qualidade da argumentação deve ser verificada, do lado das partes, nas petições, mas também pode ser averiguada no conteúdo das decisões judiciais que acompanharam o paradigma.

E por último, a diversidade dos argumentos como elemento para se chegar à completude da discussão é parâmetro garantidor do respeito ao princípio do contraditório efetivo. Como o alcance do precedente firmado pelo julgamento por amostragem atingirá um elevado número de indivíduos, com realidades diferentes, em regiões distintas e com argumentações diversas, é imprescindível que se leve ao conhecimento do órgão julgador uma diversidade de argumentos não só de um polo do processo, mas de todos; não só de uma localidade, mas de todo o lugar onde se tenha a mesma discussão jurídica.

Neste sentido, o artigo 1.036 do Código de Processo Civil foi primoroso ao prever que somente podem ser selecionados recursos admissíveis que contenham abrangente argumentação e discussão a respeito da questão a ser decidida (BRASIL, 2015, n.p.).

É crucial para o contraditório que os diversos argumentos das diversas pessoas afetadas pelo precedente em julgamento por amostragem possam influenciar na formação do precedente e, consequentemente, na resolução da lide.

Para isso é recomendável que sejam selecionados, não apenas um caso piloto, mas vários processos paradigmas de diversas e qualificadas teses opostas a fim de materializar a completude da discussão.

Neste sentido, acertada a decisão do Superior Tribunal de Justiça ao editar a Resolução 8/2008, que, em seu art. $1^{\circ}, \S 1^{\circ}$, estipula que como casos pilotos serão selecionados pelo menos 1 (um) processo de cada relator e, dentre estes, os que contiverem maior diversidade de fundamentos no acórdão e de argumentos no recurso especial.

\subsection{Contraditório Efetivo no Caso-Piloto}

Ao lado da completude da discussão, constitui também baliza de garantia do contraditório, logicamente, a existência de efetivo contraditório durante todo o processo originário. Ou seja, devese rejeitar escolher casos pilotos ou modelos em que tenha havido revelia, ou precariedade de contra argumentações tanto fáticas como de questões de direito. Sobre o tema conclui Antonio do Passo Cabral: 
Assim, a conclusão que se pode chegar é que a completude da argumentação não pode remeter apenas `as alegações das partes, do MP e intervenientes, mas deve também levar-nos a verificar a fundamentação da decisão judicial. De fato, a dialética do contraditório-influência, no trinômio informação-expressão-consideração, impõe que, para a escolha da causa piloto, a efetividade do contraditório compreenda também a análise sobre os atos do Estado-juiz (CABRAL, 2017, p. 54.).

No mesmo contexto, a exigência de um contraditório efetivo impõe não selecionar um processo em que a questão, apesar de amplamente debatida pelos sujeitos processuais, não tenha sido detalhada e analiticamente enfrentada em extensão e profundidade pelo magistrado.

\subsection{Ampliada cognição no processo}

A efetividade do contraditório no julgamento por amostragem passa também por uma atividade cognitiva irrestrita no caso piloto ou modelo, com amplos poderes de debates entre as partes, oferecimento de argumentos, exceções e produção de provas. É necessário que se evite processos paradigmas onde tenha havido sumariedade na fase de conhecimento.

A restrição cognitiva pode ser no plano horizontal quando certas matérias são subtraídas da apreciação judicial. Bem como, pode haver restrições cognitivas no campo vertical, que se refere à profundidade da atividade discursiva sobre cada uma das questões debatidas.

Assim, para se garantir um julgamento por amostragem dentro do contraditório substancial, não se devem ser selecionados como causa-piloto ou modelo, certos procedimentos que restrinjam a produção da prova técnica como nos Juizados Especiais (arts. 3o e 32 da Lei 9.9099/95). É também o caso do inventário e partilha (arts. 612; $627 \S \S 1^{\circ}, 2^{\circ}, 3^{\circ} ; 641, \S 2^{\circ}$, todos do CPC) (CABRAL, 2017, p. 57.).

Escolher como caso piloto ou modelo processos de cognição restrita é limitar o contraditório dialético a um debate incompleto e superficial, que certamente não legitimará o precedente a estabilizar e a uniformizar a questão de direito em discussão.

\subsection{Participação dos terceiros afetados pelo provimento na formação da decisão judicial (pluralização do debate)}

Como visto, o objetivo primordial do julgamento por amostragem consiste em uniformizar e estabilizar os provimentos jurisdicionais de forma íntegra, coerente e célere, estendendo os efeitos de seus precedentes para além das partes do processo piloto.

Desta forma, deve-se garantir aos terceiros, que claramente não integrantes da causa piloto ou modelo, mas que serão atingidos pelo precedente vinculante oriundo do julgamento por amostragem a possibilidade de, mediante o exercício do contraditório, levar previamente à apreciação do julgador seus argumentos ou, posteriormente à formação do precedente, ter o direito de interpor os recursos cabíveis contra a tese firmada, exercendo o contraditório diferido.

Liebman (1945, p. 77) argumenta que o círculo de relações e de pessoas em que operará o comando contido numa sentença não pode ser e não é preventivamente determinado em abstrato, mas dependerá do uso que em concreto fizerem as partes da sentença, da qualidade e do número das controvérsias que poderão surgir no futuro. Além de que terá por condição certo modo de ser das relações jurídicas, o nexo e o grau de ligação entre elas existentes.

O precedente firmado no julgamento por amostragem de recursos repetitivos evidentemente amplia os seus efeitos, fazendo repercutir suas consequências sobre a esfera jurídica de terceiros - não intervenientes no processo. Mas isso não pode significar que esses terceiros se submetam aos efeitos negativos da formação do precedente sem que lhes caiba qualquer possibilidade de influenciar, previamente ou posteriormente, no julgado. 
Sobre esta problemática, o Código de Processo Civil trouxe dispositivos que permitem a participação de pessoas que demonstrem interesse ou possam ser atingidas pela formulação do precedente.

O artigo 983 do CPC dispõe que o relator ouvirá as partes e os demais interessados, inclusive pessoas, órgãos e entidades com interesse na controvérsia, que, no prazo comum de 15 (quinze) dias, poderão requerer a juntada de documentos, bem como as diligências necessárias para a elucidação da questão de direito controvertida (BRASIL, 2015, n.p.).

No mesmo caminho, o art. 1.038 do CPC preleciona que o relator poderá solicitar ou admitir manifestação de pessoas, de órgãos ou de entidades com interesse na controvérsia, considerando a relevância da matéria e consoante dispuser o regimento interno. Com base no efetivo contraditório deve-se entender tal preceito não como uma faculdade do relator, mas sim como um direito subjetivo do terceiro interessado em influenciar na formação do precedente.

Sobre o aspecto hermenêutico constitucional da questão, Peter Härbele (1997, p. 13.) aduz que "quem vive a norma acaba por interpretá-la ou pelo menos co-interpretá-la", sendo então conivente com o posicionamento de que a norma não cabe somente ser analisada pelo Estado, porque os demais integrantes da sociedade possuem o mesmo direito.

Trata-se de verdadeiro mecanismo de pluralização do debate, sob uma perspectiva democrática de participação ativa da sociedade qualificando-se como um fator de legitimação social da formação do precedente judicial.

\subsection{Representatividade adequada dos interessados}

Como visto, para se adotar um precedente judicial vinculante a vários processos através da técnica de julgamento por amostragem é preciso mitigar qualquer risco a implementação do efetivo contraditório.

Nessa perspectiva, Antônio do Passo Cabral propõe:

(a) se paralelamente estiver tramitando processo coletivo fundado na mesma discussão jurídica, deve este ser preferido aos processos individuais. E, (b) se vários processos coletivos estiverem tramitando, devem ser preferidos aqueles ajuizados por órgãos independentes (que atuem com base no interesse público e sem hierarquia), e aqueles defensores de direitos das comunidades de substituídos mais amplas em termos geográficos e quantitativos (absent clas members) (CABRAL, 2017 p. 61).

Neste sentido, quanto mais ampla a representatividade adequada na cognição do caso piloto maior será a legitimação política e social do precedente judicial firmado, reduzindo sensivelmente o descontentamento com a questão jurídica decidida e contribuindo pela maior aceitação do efeito vinculante do precedente.

Assim, o ideal é que uma das partes postulantes, seja órgão ou entidade, congregue dentre seus afiliados porção significativa tanto qualitativamente quanto quantitativa dos membros dos grupos sociais a serem afetados pela decisão a ser proferida.

Por fim, verifica-se na sistemática do julgamento por amostragem um interesse público na fixação do precedente. Tal interesse, em certa medida, pode confundir-se com os das ações coletivas, razão pela qual a escolha destas como sendo caso-piloto, aumenta a probabilidade da formação de um precedente com legitimidade social e aderente com o efetivo contraditório. 


\section{Considerações Finais}

A Constituição Federal de 1988, em seu rol vanguardista de direitos e garantias fundamentais no seu corpo, trouxe instrumentos a qualquer do povo a Justiça, instituindo um modelo de democracia participativa. O Judiciário se inseriu nesse contexto como espaço democrático.

Porém, o reconhecimento de novas gerações de direitos e a significativa ampliação do acesso à justiça decorrentes do próprio Estado Democrático de Direito, juntamente com uma cultura de litigiosidade, fizeram com que o Poder Judiciário recebesse sobrecarrega de demandas nas últimas décadas, o que foi agravado pela falta de resposta dos normas que regulam o processo coletivo brasileiro.

Atingiu-se a quantidade crítica de massa de sujeitos que demandam uma proteção do Sistema Jurídico, o que impôs a modificação em um dos três aspectos do Direito (fato, valor e norma).

Assim, em busca de salvaguardar o interesse coletivo de maior segurança jurídica e por uma reposta célere do Judiciário, a partir da Constituição Federal começou-se a introduzir no ordenamento jurídico pátrio o exercício da jurisdição com base nos "precedentes judiciais, o que foi consolidado no CPC de 2015 através da técnica de julgamento por amostragem e obediências aos precedentes vinculantes.

A ideia central do julgamento por amostragem consiste em uniformizar e acelerar a conclusão do litígio com a aplicação dos precedentes para inibir recursos, autorizando a extensão das conclusões de um caso piloto ou modelo para as demais ações em que se discute idêntica controvérsia.

Porém, essa nova forma de atuação do Judiciário dentro do Estado Constitucional deve acompanhar a mudança na postura participativa das partes no processo. Como consequência do Estado Democrático de Direito houve uma mudança na estrutura "Estado-Juiz X Partes", em que as partes deixam de lado a condição passiva da decisão judicial e passam a influir decisivamente no ato decisório por meio do contraditório substancial.

Assim é que, surge uma nova percepção do contraditório que abrange não apenas a mera audiência bilateral das partes, mas que contempla o direito-poder das partes de influenciar decisivamente na formação do provimento jurisdicional. Acepção mais que democrática do princípio constitucional.

Constata-se que a aplicação da técnica de julgamento por amostragem pode trazer impactos positivos para os jurisdicionados com a uniformização da aplicação da jurisprudência e redução do tempo de tramitação dos processos.

Todavia, caso a o julgamento por amostragem seja feito de modo superficial e mecânico há um sério risco de lesão ao Contraditório Substancial. Isto porque, existe uma séria dificuldade material de se garantir, a todos atingidos pelos efeitos da formação dos precedentes, mecanismos e poderes de atuação substancial no processo piloto ou modelo.

É importante destacar que a garantia do contraditório não constitui barreira intransponível para a celeridade processual. Pelo contrário, o debate judicial argumentativo de qualidade contribui para a redução do tempo processual, na medida em que fomenta precedentes judiciais com legitimidade e solidez.

De tudo, fica a necessidade da observância das balizas garantidoras do contraditório na sua vertente substancial, mesmo quando em momento diferido, quais sejam: (a) a quantidade, a qualidade e a diversidade da argumentação do caso piloto (completude da discussão), (b) o contraditório efetivo na causa piloto, (c) a ampliada cognição no processo, (d) a participação dos terceiros afetados pelo provimento na formação da decisão judicial e (e) a representatividade adequada dos interessados.

Portanto, chega-se à conclusão de que é possível se uniformizar e estabilizar a jurisprudência com a celeridade processual, sem que isso importe em prejuízo ao princípio constitucional do contraditório. Principalmente, se levar em consideração que o postulado do contraditório efetivo, não é um valor absoluto e imutável, podendo então ser diferido ou, até mesmo, mitigado, desde que não represente efetivo prejuízo à parte. 


\section{Referências}

BRASIL. Constituição da República Federativa do Brasil. 1988. Disponível em: http://www.planalto. gov.br/ccivil 03/constituicao/constituicao.htm. Acesso em: 23 jan. 2021.

BRASIL. Código de Processo Civil Brasileiro. 1973. Disponível em: . Acesso em: 25 jan. 2021.

BRASIL. Código de Processo Civil Brasileiro. 2015. Disponível em: . Acesso em: 25 jan. 2021.

CABRAL, Antonio do Passo. A escolha da causa-piloto nos incidentes de resolução de processos repetitivos. In: Coleção Grandes Temas do Novo CPC. v.10. Salvador: Juspodivm, 2017.

CARDOSO, Juliana Provedel. O modelo brasileiro de processo coletivo: as ações coletivas e o julgamento de casos repetitivos, $1^{\underline{a}}$ ed. Salvador: Juspodivm, 2018.

DAMASCENO, Kleber Ricardo. O novo contraditório e o processo dialógico: aspectos procedimentais do neoprocessualismo. Dissertação (Mestrado em Direito). Programa de Mestrado em Ciência Jurídica. Universidade Estadual do Norte do Paraná. Jacarezinho, 2010.

DIDIER Jr, Fedie; CUNHA, Leonardo Carneiro da. Coleção Grandes Temas do Novo CPC. v.10. Salvador: Juspodivm, 2017.

DINAMARCO, Cândido Rangel. Instituições de direito processual civil. São Paulo: Malheiros, 2002.

GRECO, Leonardo. Estudos de Direito Processual. Coleção José do Patrocínio. Ed. Faculdade de Direito de Campos, 2005.

GRECO, Leonardo. Garantias Fundamentais do Processo: o Processo Justo. Ed. Faculdade de Campos. Coleção José do Patrocínio. 2005.

GREENE, Brian. A realidade oculta: universos paralelos e as leis profundas do cosmo. José Viegas Jr [trad.]. São Paulo: Companhia das Letras, 2012.

GRINOVER, Ada Pellegrini. Os princípios constitucionais e o Código de Processo Civil. São Paulo: José Bushatsky Editor, 1975.

HARBELE, Peter. A Sociedade Aberta dos Intérpretes da Constituição: Contribuição par Interpretação Pluralista e Procedimental da Constituição. Porto Alegre: Editora Sérgio Antonio Fabris, 1997.

HAWKING, Stephen. O Universo numa casca de noz. Trad. Cassio de Arantes Leite. Rio de Janeiro: Intrínseca, 2016.

LIEBMAN, Enrico Tullio. Eficácia e autoridade da sentença. Alfredo Buzaid; Benvindo Aires [trad.]. Rio de Janeiro: Forense, 1945.

MARINONI, Luiz Guilherme. A ética dos precedentes: justificativa do novo CPC. Revista dos Tribunais, 2016.

MARINONI, Luiz Guilherme. Mitidiero, Daniel. O Projeto do CPC: crítica e propostas. São Paulo: Revista dos Tribunais, 2010.

MENDES, Gilmar Ferreira. Jurisdição constitucional. 4. ed. São Paulo: Saraiva, 2005.

MENDES, Gilmar Ferreira. O papel do Senado Federal no controle de constitucionalidade: um caso clássico de mutação constitucional. Revista de Informação Legislativa, 162. 2004.

NADER, Paulo: Introdução ao estudo do direito. 36 a ed. Rio de Janeiro: Forense, 2014.

NERY JUNIOR, Nelson. Princípios do processo civil na Constituição Federal. 8. ed. São Paulo: Editora Revista dos Tribunais, 2004.

NUNES, Dierle. Novo CPC consagra concepção dinâmica do contraditório. 2018. Disponível em: https://www.conjur.com.br/2013-out-08/dierle-nunes-cpc-consagra-concepcao-dinamica. Acesso em: 17 jul. 2018. 
PESSOA, Flávia Moreira Guimarães. Constituição e Processo. Aracaju: Evocati, 2014.

REALE, Miguel. Lições preliminares de direito. 25 $5^{\underline{a}}$ ed. São Paulo: Saraiva, 2001.

ROQUE, André Vasconcelos. Ações coletivas e procedimentos para a resolução de casos repetitivos: Qual o espaço destinado a cada um? Procedimentos de resolução de casos repetitivos. In: Coleção Grandes Temas do Novo CPC. v.10. Salvador: Juspodivm, 2017.

ROXIN, Claus. Derecho penal. Parte general. Fundamentos. La estructura de la teoría del delito. Madrid: Civitas, 2006.

SILVEIRA NETO, Antonio. Conflitos de Massa e Gestão dos Processos Judiciais: Uma Proposta Da Associação Dos Magistrados Brasileiros. In: As demandas repetitivas e os grandes litigantes: possíveis caminhos para a efetividade do sistema de justiça brasileiro. Enfam, 2016.

STJ. RECURSO ESPECIAL: REsp 1.721.705- SP. 2018. Relator: Ministra Nancy Adrighi. Disponível em: https://stj.jusbrasil.com.br/jurisprudencia/622839864/recurso-especial-resp-1721705sp-2017-02673838/inteiro-teor-622839868? ref=juris-tabs. Acesso em: 14 out. 2018.

TUCCI, José Rogério Cruz e. Precedente judicial como fonte do direito. São Paulo: Revista dos Tribunais, 2004. 